\title{
Políticas Culturais e Território na América Latina: Diálogos conceituais entre Néstor García Canclini, Rodolfo Kusch e Milton Santos
}

\section{Políticas Culturales y Territorio en América Latina: Diálogos conceptuales entre Néstor García Canclini, Rodolfo Kusch y Milton Santos}

\author{
Cultural Policies and Territory in Latin America: Conceptual dialogues \\ between Néstor García Canclini, Rodolfo Kusch and Milton Santos
}

\author{
Juan Ignacio Brizuela ${ }^{1}$ \\ José Márcio Barros²
}

Palavras chave:

Políticas culturais

Território

Néstor García Canclini

Rodolfo Kusch

Milton Santos
Resumo:

Começamos este artigo com uma recapitulação, em três momentos, do conceito de políticas culturais elaborado por Néstor García Canclini. Destacamos três textos (e contextos) que entendemos serem chaves no desenrolamento conceitual deste autor no campo das políticas culturais. O primeiro é o artigo "Políticas Culturais na América Latina", publicado em português em 1983. O segundo momento aparece na introdução à coletânea "Políticas Culturales en América Latina" de 1987, onde García Canclini registra a sua primeira sistematização conceitual mais densa. $E$ finalmente, um terceiro texto em "Definiciones en transición", de 2001, onde são acrescentadas algumas questões inéditas ao conceito de 1987, incluindo categorias de análise sócio-espacial como geocultura e o caráter transnacional dos processos simbólicos e materiais mais recentes. Considerando estas mudanças conceituais, dialogamos com dois pensadores latino-americanos que nos ajudam a relacionar, desde diversos campos do conhecimento, geocultura, território e políticas culturais: Rodolfo Kusch e Milton Santos. Interessa-nos refletir sobre a atualidade destas construções conceituais, buscando contribuir com o estudo das políticas culturais contemporâneas no contexto latinoamericano. Para concluir, registramos distintas experiências realizadas por estudiosos contemporâneos da região no intuito de continuar discutindo as relações possíveis entre território e políticas culturais na América Latina. 


\begin{abstract}
Resumen:
Comenzamos este artículo con una recapitulación, en tres momentos, del concepto de políticas culturales elaborado por Néstor García Canclini. Destacamos tres textos (y contextos) que entendemos son claves en el desenvolvimiento conceptual de este autor en el campo de las políticas culturales. El primero es el artículo "Políticas Culturais em América Latina", publicado en portugués en 1983. El segundo momento aparece en la introducción a la colección de artículos "Políticas Culturales en América Latina" de 1987, donde García Canclini registra su primer sistematización conceptual más densa. Y, finalmente, un tercer texto "Definiciones en transición", de 2001, donde son acrecidas algunas cuestiones inéditas al concepto de 1987, incluyendo categorías de análisis socio-espacial como geocultura y el carácter transnacional de los procesos simbólicos y materiales más recientes. Considerando estos cambios conceptuales, dialogamos con dos pensadores latinoamericanos que nos ayudan a relacionar, desde diversos campos del conocimiento, geocultura, territorio y políticas culturales: Rodolfo Kusch y Milton Santos. Nos interesa reflexionar sobre la actualidad de estas construcciones conceptuales, buscando contribuir con el estudio de las políticas culturales contemporáneas en el contexto latino-americano. Para concluir, registramos distintas experiencias realizadas por estudiosos contemporáneos de la región con el propósito de continuar discutiendo las relaciones posibles entre territorio y políticas culturales en América Latina.
\end{abstract}

\section{Palabras clave:}

Políticas culturales

Territorio

Néstor García Canclini

Rodolfo Kusch

Milton Santos

\section{Keywords:}

Cultural Policies

Territory

Néstor García Canclini

Rodolfo Kusch

Milton Santos

\section{Abstract:}

We started this article with a recapitulation, in three times, on the concept of cultural policies elaborated by Néstor García Canclini. We highlight three texts (and contexts) that we mean keys on the conceptual learning of this author in the field of cultural policies. First it's the article "Politicas Culturais em América Latina", published in portuguese in 1983. The second moment appears at the introduction of the collection of articles untitled "Políticas Culturales en América Latina" of 1987, where García Canclini records his first conceptual systematization. And finally, a third moment appointed on the article "Definiciones en transición" in 2001, where inedited points are increased on the concept of 1987, including categories of social-spatial analyze such as geoculture and the transnational character of the recent symbolic and material processes. Considering this conceptual changes, we dialogue with two latin-american thinkers that will help, from diverse fields of knowledge, to relation geoculture, territory and cultural policies: Rodolfo Kusch and Milton Santos. We aim to reflect of the actuality of these conceptual constructions, seeking to contribute on the study of contemporary cultural policies in Latin American context. To conclude, we recorded some differents experiences performed by contemporary scholars of the region with the purpose of continuing the discussion of the relationships between territory and cultural policies in Latin America. 


\section{Políticas Culturais e Território na América Latina: Diálogos conceituais entre Néstor García Canclini, Rodolfo Kusch e Milton Santos}

É difícil pensar sobre o campo de estudos em políticas culturais na América Latina sem referir-nos a Néstor García Canclini. Doutor em filosofia pela Universidad Nacional de La Plata - UNLP, Argentina (1975) e pela Universidade de Paris em França (1978), o pesquisador argentino elaborou uma definição de políticas culturais nos anos 1980 que, mais de trinta anos depois, se mantém com atualidade e com um grau de reconhecimento invejável no campo de estudos da cultura. Se nem todos os estudiosos contemporâneos das políticas culturais concordam totalmente com a sua definição, é quase impossível que a desconheçam, sendo referência básica em qualquer curso de formação desta área nos países latino-americanos e em muitas outras partes do mundo também.

Os três momentos que destacaremos aqui em sua construção conceitual acerca das políticas culturais estão presentes nos textos "Políticas Culturais na América Latina", publicado em português em 1983, na introdução à coletânea "Políticas Culturales en América Latina" de 1987 - na qual García Canclini registra a sua primeira sistematização conceitual - e, finalmente, no texto "Definiciones en transición" de 2001, onde são acrescentadas algumas questões inéditas ao conceito de 1987; incluindo categorias de análise sócio-espacial como geocultura e o caráter transnacional dos processos simbólicos e materiais mais recentes. Considerando estas mudanças conceituais, dialogamos com dois pensadores latino-americanos que nos ajudam a relacionar, desde diversos campos do conhecimento, geocultura, território e políticas culturais: Rodolfo Kusch e
Milton Santos. Interessa-nos refletir sobre a atualidade destas construções conceituais, buscando contribuir com o estudo das políticas culturais contemporâneas no contexto latino-americano. Para concluir, registramos distintas experiências realizadas por estudiosos contemporâneos da região no intuito de continuar discutindo as relações possíveis entre território e políticas culturais na América Latina.

\section{3 - Políticas Culturais na América Latina}

No primeiro texto aqui destacado, García Canclini (1983) fala a partir do próprio contexto histórico-geográfico. $\mathrm{O}$ autor registra as expectativas revolucionárias dos anos 1960 após a revolução cubana, as reações conservadoras cívico-militares dos anos 1970 com golpes no Brasil, na Bolívia, Chile, Argentina e Uruguai e as idas e voltas das lutas populares das grandes maiorias destes países diante das receitas neoconservadoras do economista estadunidense Milton Friedman, referência da perspectiva liberal, que começavam a ser aplicadas com força nos países do continente (p. 39). Nesse contexto, o horizonte traçado para as políticas culturais pelo jovem professor era claro: lutar contra o capitalismo e imperialismo no intuito de possibilitar uma via socialista a partir de uma política popular na cultura (p. 48 e 51).

Para o autor, discutir políticas culturais é pensar sobre a sociedade em que queremos viver. Sendo assim, o texto busca:

[...] revisar as concepções do nacional- popular atuantes na América Latina e sua relação com as práticas, com as políticas culturais, como parte da discussão sobre o tipo de sociedade que queremos e sobre os erros que obstaram as lutas populares (p. 40). 
Registra-se um entendimento sobre a cultura relativamente comum entre os antropólogos que a estudam "como um conjunto de fenômenos que contribuem, mediante a representação ou reelaboração simbólica das estruturas materiais, para compreender, reproduzir ou transformar o sistema social" (Ibidem, p. 40). Sendo assim, o âmbito da cultura não se restringe às chamadas "belas artes", livros ou concertos, mas inclui os modos de viver, pensar, comer, imaginar e fazer política de uma população determinada. Isto é, formas e práticas que distinguem a um povo e lhes dão identidade.

Cinco são as concepções do nacional-popular estudadas pelo pesquisador argentino: a) biológico-telúrica; b) partidária do Estado; c) mercantil; d) militar e; e) histórico-popular. $\mathrm{O}$ autor busca compreender de forma crítica os paradigmas ideológicos que sustentam estas concepções examinando as suas consequências práticas; ou seja, a execução das políticas culturais. Sobre a definição conceitual das políticas culturais, foco principal deste texto, ela não aparece de forma explícita, mas já podemos observar alguns delineamentos que serão retomados pelo autor poucos anos depois.

\section{7 - Políticas Culturales en América Latina}

Na introdução desta coletânea, publicada em 1987, García Canclini realiza um balanço dos estudos latino-americanos sobre políticas culturais desde o final dos anos 1960 e procura argumentar a respeito de por que são cada vez mais centrais este tipo de discussões e práticas no final dos anos 1980, nos países do continente. Por um lado, afirma o autor, as ações estatais no campo da cultura começam a ganhar algum tipo de coerência similar à coordenação que pode ser encontrada nas políticas setoriais econômicas, de saúde ou moradia. Isto pode ser observa- do nas ações do governo cívico-militar do Brasil com a criação do Conselho Federal de Cultura em 1967 e na formulação da Política Nacional de Cultura em 1973-75 e também na Argentina, já no processo de redemocratização, com o Plano Nacional de Cultura 1984-1989 (p. 14 e 22) ${ }^{3}$.

Por sua vez, afirma o autor, estudiosos das ciências sociais, no seu sentido mais amplo, e organismos internacionais, como a UNESCO, começam a considerar temáticas relacionadas ao campo da cultura para melhor entendimento das sociedades da época junto com as questões econômicas e políticas, procurando aplicar metodologias de pesquisa tão rigorosas quanto às aplicadas a outros campos de conhecimento social "superando así la época en que este campo sólo merecía especulaciones filosóficas y ensayos intuitivos" (p. 15) ${ }^{4}$. O estudioso destaca, também, o papel crescente de atores não estatais na gestão das políticas culturais, sejam estes tanto grandes corporações empresariais transnacionais e outros agentes do mercado capitalista quanto agrupações culturais de base, movimentos indígenas, comunitários e populares, entre muitos outros, invisibilizados pelo Estado e também pelas chamadas indústrias culturais. Neste contexto, surgem estudos interessados em compreender as bases culturais dos movimentos revolucionários e das culturas populares da região (p. 24), com destaque para os pensadores nucleados no CLAC$\mathrm{SO}^{5}$, menos preocupados pelas análises políticas e econômicas tradicionais e mais inquietados na redefinição e ampliação do conceito de cultura, que deixa de designar unicamente às linguagens artísticas da elite. Estes pesquisadores estudam, entre outras questões, a reprodução e transformação das operações simbólicas que acontecem no seio das comunidades, que se traduzem em diversos modelos de sociedade e que, por sua vez, estão sendo propostos e disputados pelos distintos grupos de interesses culturais (p. 25-26). 
G. Canclini lamenta que a conjuntura econômica das sociedades latino-americanas da época seja de crise (quando América Latina não esteve em crise?), agravada pela implantação do modelo liberal neoconservador que reduz fundos públicos para a educação, para pesquisar e difundir bens culturais, que diminui os salários e aumenta as condições de precarização dos trabalhadores... Enfim, que impossibilita as condições para uma efetiva democracia cultural: "[e]n el momento en que comprendemos mejor el papel que la cultura puede cumplir en la democratización de la sociedad estamos en las peores condiciones para desarrollarla, redistribuirla, fomentar la expresión y el avance de los sectores populares" (p. 26). Sendo assim, afirma o autor, se o trabalho cultural é necessário para enfrentar democraticamente as contradições do desenvolvimento, a crise da cultura deve tratar-se junto com a que se vive na economia e na política. É a partir deste contexto e desta conjuntura, e após esta sólida argumentação que o autor registra a sua já clássica conceituação:

Entenderemos por políticas culturales al conjunto de intervenciones realizadas por el Estado, las instituciones civiles y los grupos comunitarios organizados a fin de orientar el desarrollo simbólico, satisfacer las necesidades culturales de la población y obtener consenso para un tipo de orden o de transformación social (1987, p. 26).

Nesta definição, chama a atenção o fato de afirmar não ser o Estado o único agente das políticas culturais, envolvendo também diversas instituições civis e comunitárias organizadas - pensando, seguramente, nos mais variados movimentos sociais e de populações originárias que existem na América Latina. Ademais, os programas e ações estabelecidos em uma política cultural procuram, segundo o autor, satisfazer as necessidades culturais da população. Finalmente, estas políticas são aplicadas para obter um determinado consenso, seja para manter uma ordem ou cânone preestabelecido, ou para construir vias alternativas que permitiriam uma transformação desse status quo.

Essa questão nos remete à possibilidade de reconhecer a especificidade das políticas culturais no contexto das políticas públicas, configurando uma trajetória de pesquisas e um conjunto de instrumentos e ferramentas metodológicas elaboradas para dar conta desta singularidade. Com isto não estamos querendo dizer que a produção intelectual sobre políticas públicas não tenha nenhuma utilidade para o estudo e avaliação das políticas culturais. Esta abordagem é importante, claro, ainda mais quando analisamos e avaliamos políticas estatais ou governamentais para a área da cultura. O que afirmamos é a partir de $\mathrm{G}$. Canclini, que o estudo das políticas culturais não pode ser simplificado a uma subcategoria dos estudos das políticas públicas.

\section{1 - Definiciones en transición}

O que mudou na conceituação de García Canclini sobre políticas culturais entre os textos de 1987 e 2001? A mudança espaço-temporal antes da queda do muro de Berlim a outro contexto no inicio do século XXI onde não tinha acontecido, ainda, a queda das torres gêmeas de Nova lorque, nos Estados Unidos, em 11 de setembro de 2001, deveria significar uma grande mudança ${ }^{6}$. Este artigo, conforme já foi registrado no começo do texto, se intitula "Definiciones en transición". Nele, o autor faz um comentário que se tornou amplamente conhecido afirmando que, aparentemente, o único consenso que existe entre os estudiosos da cultura é que não há consenso sobre como defini-las ${ }^{7}$. Porém, matiza o pesquisador, é necessário construir definições operativas, ainda que sejam provisórias, inseguras e, nós acrescentamos, intuitivas, para seguir 
pesquisando e fazendo políticas culturais $^{8}$. Citamos, a seguir, o verbete correspondente à noção em discussão:

Políticas Culturales: Los estudios recientes tienden a incluir bajo este concepto al conjunto de intervenciones realizadas por el estado, las instituciones civiles y los grupos comunitarios organizados a fin de orientar el desarrollo simbólico, satisfacer las necesidades culturales de la población y obtener consenso para un tipo de orden o de transformación social (p. 65, grifado original).

Nesta conceituação de 2001 G. Canclini reproduz sua definição de 1987, acrescentando, algo extremamente importante, o caráter transnacional das trocas culturais: "Pero esta manera de caracterizar el ámbito de las políticas culturales necesita ser ampliada teniendo en cuenta el carácter transnacional de los procesos simbólicos y materiales en la actualidad" (p. 65, grifo nosso). O que isso significa? Basicamente o reconhecimento do transbordamento dos espaços nacionais em função dos fluxos comunicacionais e dos reordenamentos econômicos:

No puede haber políticas sólo nacionales en un tiempo donde las mayores inversiones en cultura y los flujos comunicacionales más influyentes, o sea las industrias culturales, atraviesan fronteras, nos agrupan y conectan en forma globalizada, 0 al menos por regiones geoculturales o lingüísticas. Esta transnacionalización crece también, año tras año, con las migraciones internacionales que plantean desafíos inéditos a la gestión de la interculturalidad más allá de las fronteras de cada país (p. 65, grifo nosso).

Podemos pensar, com G. Canclini, que as indústrias culturais dos anos 1970 e 80 - e as políticas culturais estatais não conseguiam atravessar fronteiras para agrupar-nos e conectar-nos de forma globalizada ou ao menos, como esclarece o autor, por regiões geoculturais e linguísticas. O fenômeno de transnacionalização aos quais estamos "submetidos" acontece, também, pelo aumento das migrações internacionais, o que gera desafios inéditos, segundo o pesquisador, para a gestão da interculturalidade - interessante provocação - além das fronteiras dos países. Em síntese, ao considerar o caráter transnacional dos processos simbólicos e materiais da contemporaneidade, García Canclini incorpora vários elementos que não se mostravam presentes em 1987, quando da primeira aproximação ao conceito de políticas culturais.

Contudo, o que mais nos interessa trabalhar nesta "nova" definição é a questão das regiões geoculturais, elemento que consideramos estar implícito na sua proposta de 1987 quando contextualiza sua reflexão sobre políticas culturais "na" América Latina. $E$ nos chama a atenção esta opção pelo "geo" cultural dado não ser comum a presença desta categoria nos estudos da cultura e ainda menos nas políticas culturais. Desde quando o elemento geográfico importa na compreensão deste fenômeno? Quer dizer, a ideia de América Latina foi estudada como proposta política, econômica e cultural nos últimos tempos, mas não como região geocultural. Aliás, que significa região geocultural? Qual a relação entre geografia, território e cultura? Estas questões aparecem, também, em um livro posterior em que García Canclini participa junto com reconhecidos pesquisadores como Jesús Martín-Barbero e Rodolfo Stavenhagen - entre outros -, intitulado "El Espacio Cultural Latinoamericano" (2003), coordenado pelo pesquisador chileno Manuel Garretón e editado pelo Convênio Andrés Bello. A tese principal do livro está fundamentada na seguinte afirmação:

El mundo en este siglo se constituirá no en torno a lo geopolítico ni a lo 
geoeconómico, sino principalmente en torno a lo geocultural: será apropiado, construido, distribuido entre diferentes espacios culturales, y América Latina debe ser uno de ellos (p. 7).

Nesse trabalho coletivo, os autores acreditam na existência de uma imagem do latino-americano fruto da geografia, da cultura, do idioma, da história, da política e de um estilo de vida que, conjugado com outros numerosos elementos, definem certa singularidade do latino-americano. Porém, a integração deste espaço cultural é frágil, mesmo com mais de duzentos anos de trajetória compartilhada. O conhecimento deste espaço, afirmam os pesquisadores, não faz parte da cultura comum dos latino-americanos no século $\mathrm{XXI}$. $\mathrm{E}$ isto gera um problema porque é indispensável o reconhecimento do espaço onde se vive, a história comum e a consciência de que se forma parte de um projeto cultural, isto é, de uma cultura e de uma sociedade maior aos projetos nacionais, por mais diversos que estes sejam (p. 47).

O texto coletivo apresenta, também, uma definição operativa sobre a noção de espaço cultural:

El espacio cultural es un concepto complejo y puede significar varias cosas. La noción de espacio sugiere territorios geográficamente delimitados, visibles, identificables, pero hay también espacios que no son territorialmente ubicables, o que lo son sólo parcialmente. Hay espacios y circuitos culturales que no se reducen a una distribución, lugares o límites geográficos, que trascienden las naciones e incluso el marco de un conjunto de naciones-Estados. [...] El espacio cultural, en su concepto más amplio, es aquel que incluye lo físico territorial y lo no territorial incluyendo lo comunicacional y lo virtual (p. 35, grifo nosso).
Em um mundo contemporâneo organizado em blocos geoculturais, um dos quais seria o espaço cultural latino-americano, os limites nacionais são insuficientes para o estudo das políticas culturais, o caráter transnacional dos processos simbólicos e materiais atuais devem ser considerados enquanto um espaço cultural comum maior, supranacional, que inclui dimensões físico-territoriais e "não territoriais" (como circuitos comunicacionais e virtuais, segundo Garretón et al). Podemos questionar se esta separação proposta pelos autores entre espaço cultural "territorial" - que seria a dimensão físico-material do continente, a área geográfica dos Estados Nacionais - e o espaço cultural "não territorial" - que incluiria redes comunicacionais e virtuais "desterritorializadas" - é adequada. Autores como Haesbaert (2008), entre outros, defendem a ideia de novas territorialidades no mundo globalizado - como a noção de territórios-rede - mas não concordam que existam espaços culturais "não territoriais" ou "desterritorializados", conforme analisaremos mais na frente. O que muda no século XXI não seria só o estudo das políticas culturais; o fazer, também, deveria ser diferente:

[...] las condiciones en que se pueden hacer políticas culturales son distintas a cuando se hablaba sólo de espacios territoriales, cuando la cultura coincidía mucho más con los territorios habitados por una población, que se creía que era homogénea. Cuando existen circuitos, también hay que tener una política para éstos, pero tiene que ser otro tipo de política. Es evidente que hay una enorme fluidez entre territorio y circuito. Pero aún dentro de los países más definidamente capitalistas y globalizados, la lucha por las excepciones culturales y contra la oligopolización en algunos campos son afirmaciones de territorialidad y de control social de esa territorialidad (GARRETÓN, 2003, p. 35, grifo nosso). 
Barros (2009) afirma que uma política cultural se constitui na articulação entre as noções de territorialidade e setorialidade. Destarte, segundo o pesquisador, é necessário articular estas variáveis buscando um equilíbrio que atenda tanto à dimensão mais ampla da cultura, também chamada de perspectiva antropológica, quanto à perspectiva mais específica de organização de circuitos de produção cultural; ou seja, a dimensão sociológica categorias trabalhadas por Isaura Botelho (2001) a partir das reflexões do sociólogo chileno José Joaquin Brunner (apud BOTELHO, 2001). Tanto a abrangência territorial quanto a análise de suas características e especificidades se mostram como indispensáveis na construção (e estudo) de uma política cultural, nos distintos níveis de atuação: local, regional, nacional, transnacional e global (2009, p. 64).

Por sua vez, o pesquisador Mato (2007a) afirma em seus estudos, a necessidade de não limitar a análise das políticas culturais a um determinado tipo de atores sociais - como governos ou agências específicas de cultura de organismos estatais - nem a uma série de práticas específicas associadas às chamadas "belas artes", "culturas populares" ou às "indústrias culturais" (aliás, segundo o autor, todas as indústrias são culturais). A sua proposta de pesquisa inclui políticas e práticas de grupos comunitários e outros tipos de organizações sociais, empresariais etc. e também integra tudo aquilo que se relaciona com o caráter simbólico e de sentido das práticas sociais; em particular, através de representações sociais pesquisadas pelo autor em diferentes contextos ao longo da sua trajetória intelectual ( $p$. 15-16). Mato estabelece uma perspectiva abrangente, não setorial, que pouco é estudada e utilizada tanto no Brasil quanto em outros países latino-americanos.

Assim sendo, observamos uma preocupação nestes e outros autores em dis- cutir a importância do território e da dimensão espacial para o estudo das políticas culturais no contexto latino-americano. Para finalizar este artigo, registraremos, a seguir, algumas reflexões realizadas por distintos pensadores de diversos campos de conhecimento no intuito compreender conceitualmente as relações entre geocultura, território e políticas culturais na América Latina.

\section{Território e políticas culturais - Contribui- ções de Milton Santos e Rodolfo Kusch}

O território e as políticas culturais são, cada um por sua conta, acontecimentos sumamente instigantes que têm gerado diversos e renovados "experimentos" teórico-conceituais publicados ao longo dos últimos anos no contexto latino-americano ${ }^{9}$. Para o professor Milton Santos [1994], o estudo do território, na contemporaneidade, não deveria reproduzir a tradição herdada da modernidade de conceitos puros que permanecem por séculos quase intocáveis (2005, p. 255). Segundo ele, é necessário construir conceitos híbridos, de formas impuras, afetados espaço-temporalmente, abertos e em movimento constante:

[...] por que, então, em nossa construção epistemológica não preferimos partir dos híbridos, em vez de partir da ideia de conceitos puros? Esta é, também, a posição de Hägerstrand (1989, 1991b, p. 117) quando propõe tratar de forma simultânea o mundo da matéria $e$ o mundo do significado humano (2012, p. 101, grifo nosso).

Portanto, Santos afirma que o objeto de análise social não é o território "em si mesmo", mas o uso do território; ou seja, o território usado - nós acrescentamos: histórico, simbólico, contingente, habitadocomo quadro permanente de nossa vida $(2005, \text { p. } 255)^{10}$. "[...] já que usado, o territó- 
rio é humano" afirma o pesquisador (Ibidem, p. 257). E esta seria a sua proposta híbrida inicial, ao mesmo tempo, simbólica e material, que nos permitiria estudar a realidade territorial de forma sistêmica e integral.

A perspectiva miltoniana não considera o território apenas como um palco, um cenário passivo onde acontece a vida em sociedade. O território também "acontece". Ele surge, "retorna" - na metáfora do autor - como um ator dinâmico, em constante movimento e interação com o seu entorno cultural. Santos e Silveira [2001] afirmam que: "para definir qualquer pedaço de território devemos levar em conta a interdependência e a inseparabilidade entre a materialidade, que inclui a natureza, e o seu uso, que inclui a ação humana, isto é, o trabalho e a política" (2011, p. 247). Por conseguinte, o território usado é um território vivo, vivendo que: "[...] revela também as ações passadas e presentes, mas já congeladas nos objetos, e as ações presentes constituídas em ações" (Ibidem, p. 247).

Nutrindo-se destas considerações, o geógrafo gaúcho Rogério Haesbaert (2006) nos provoca (o que nos estimula a refletir) afirmando que as ciências sociais (re)descobriram recentemente o território só para falar de seu desaparecimento ( $p$. 26). Com raras exceções, afirma o autor, 0 espaço ${ }^{11}$ foi negligenciado nas análises das sociedades modernas. Estudos recentes sobre a chamada "desterritorialização" promovida pela globalização neoliberal ${ }^{12}$ teriam alertado sobre o enfraquecimento, ou até mesmo o desaparecimento, dos laços territoriais das sociedades atuais. Contudo, afirma Haesbaert, isto não gerou pesquisas que destacaram a importância anterior dos territórios nas sociedades agora globalizadas. Outros pesquisadores da região, como Escobar (1999, 2010), Mato (2007b) e Porto-Gonçalves (2008, 2012), também questionam o "mito da desterritorialização" no mundo contemporâneo e, concordando com Haesabert, afirmam que não existe sociedade sem território. Conforme sinalizado por Daniel Mato:

\section{[...] globalización y transnacionali- zación no necesariamente implican “desterritorialización”, y que según los casos específicos y basándose en análisis cuidadosos, habría que ha- blar en términos de transterritoriali- dad, multiterritorialidad, multilocali- zación, o reterritorialización (2007b, p. 35, grifo nosso).}

Esta multiplicidade de categorias espaciais associadas ao território nos obrigam a (re)pensar o estudo das políticas culturais desde uma perspectiva mais abrangente e, claro, territorial.

Além disso, especialistas em economia, filosofia, antropologia e outros campos do saber também têm contribuído, e muito, nas atuais abordagens territoriais cada vez mais afastadas do naturalismo ou dos estudos físico-geográficos tradicionais da modernidade. Contudo, este diálogo interdisciplinar acontecido dentro da tradição do pensamento latino-americano não parece ter tido muita visibilidade ou estudo na contemporaneidade ${ }^{13}$. Assim sendo, um dos pensadores das nossas latitudes que muito tem a contribuir nestas abordagens mais abrangentes sobre o território é o argentino Rodolfo Kusch.

Professor da Universidad Nacional de Buenos Aires (UBA) com formação em filosofia, Kusch foi invisibilizado, todavia, pelos colegas filósofos da região. Também utilizou métodos antropológicos nas suas pesquisas de campo; entretanto, era bastante crítico dos antropólogos de sua época. Dialogava, sim, com geógrafos, especialmente do campo rural; porém, tampouco suas conceituações claramente ligadas a esta disciplina - como a noção de "geocultura" - conseguiram um lugar destacado nas discussões geográficas do país ou do continente. Neste sentido, se 
bem Kusch não constrói de forma tão explícita uma abordagem territorial, acreditamos pertinente retomar algumas de suas reflexões sobre o solo, o habitat, o espaço vital e a (geo)cultura com o intuito de (re) pensar o estudo do território a partir destas inquietações mais filosóficas situadas no contexto americano.

Após realizar diversas pesquisas de campo com comunidades do norte da Argentina e do sul da Bolívia, região conhecida culturalmente como andina, Kusch [1978] se debruça sobre a importância que adquire o pensamento dos grupos culturais para compreender tudo o que se refere a eles mesmos. Segundo o autor, "[s]e trata de un pensamiento condicionado por el lugar, o sea que hace referencia a un contexto firmemente estructurado mediante la intersección de lo geográfico con lo cultural" (2012f, p. 75). Contudo, matiza o autor, afirmar que a geografia condiciona o pensamento seria muito superficial. Para ele acontece algo mais profundo. Existiria uma fundamentação filosófica que não se sabe exatamente o que seria, uma espécie de sustento "último" não racional de um grupo cultural, que ele caracteriza com o termo solo ${ }^{14}$.

La idea de un pensamiento resultante de una intersección entre lo geográfico y lo cultural conduce al problema filosófico de la incidencia del suelo en el pensamiento y abre, por consiguiente, esta pregunta: ¿Todo pensamiento sufre la gravidez del suelo, o es posible lograr un pensamiento que escape a toda gravitación? Esto lleva a una funcionalidad del pensar y ésta, por su parte, al encuentro del pensar con su suelo (Ibidem, p. 76, grifo nosso).

Assim sendo, um pensamento gravitado pelo solo constitui um núcleo seminal de conteúdo simbólico, histórico e também material; que mantém uma relação indissociável com o espaço geográfico e que produz os símbolos culturais cotidia- nos que permitem a supervivência de uma comunidade humana determinada. Kusch enuncia um paradoxo lógico quando questiona a universalidade do pensamento ocidental, afirmando sua historicidade, localidade e contingência, mas asseverando, também, a "universalidade" da gravidade do solo que sustenta o pensamento. Só que esta universalidade "deformada", contingente, histórica, localizada, afetada pelo território e pela cultura local, gera diversos solos e, neste sentido, distintas formas de pensamento. Ou seja, a universalidade da condição humana se manifesta historicamente em todas suas variantes pela união indissociável de culturas e territórios, pensamentos e solos. Em palavras do autor:

Si se logra fundar la observación de que todo pensamiento es naturalmente grávido y tiene su suelo, cabría ver en qué medida dicha gravidez crea distintas formas de pensamiento. Quizá se podría ampliar entonces todo lo que se refiere a una antropología del pensamiento, en el sentido de no establecer ad hoc un pensamiento así llamado universal, sino de descubrir en la gravidez del pensar, o sea en el suelo que lo sostiene, un cuadro real del mismo que abarque todas las variantes de su modo de ser universal. $Y$ esto simplemente porque lo universal deformado, no es ni universal, ni deformado, sino que constituye la restitución de un modelo real (lbidem, $p$. 76-77, itálica do autor, grifo nosso).

Rodolfo Kusch [1975] também problematiza se a cultura é um cultivo que, como pensadores latino-americanos, não sabemos colher, ou se na verdade a semente também está em nós mesmos, deste lado do mundo (2012e, p. 113-114). A cultura seria nosso "endereço existencial" no planeta; nela nos encontramos, nos arraigamos e sentimos que a gravidade do chão, a atração do solo, nos contempla e nos acolhe: 
Y este suelo así enunciado, que no es ni cosa, ni se toca, pero que pesa, es la única respuesta cuando uno se hace la pregunta por la cultura. Él simboliza el margen de arraigo que toda cultura debe tener [...] No hay otra universalidad que esta condición de estar caídos en el suelo, aunque se trate del altiplano o de la selva (Ibidem, p. 113, grifo nosso).

A busca de conexões entre o pensamento de Rodolfo Kusch e Milton Santos, somados aos estudos contemporâneos sobre o território citados, nos animam a refletir sobre o ponto de vista geocultural. Kusch considera o espaço geográfico coberto pelo pensamento do grupo e condicionado pelo local. Sendo assim, não cabe falar de geografia e cultura, mas de "unidade geocultural" (LANGÓN, 2005). Esta perspectiva procura o reconhecimento de outras geoculturas, outros logos e ethos, o que possibilita e exige o diálogo intercultural: "Al comprender al otro como incomprensible desde mi cultura, lo descubro éticamente como otra cultura -otra interioridad, otra vida - de distinto contenido que la mía: con otras costumbres, verdades, valores, preferencias..." (Ibidem, p. 1).

\section{A modo de conclusão}

Ao longo do texto, buscamos analisar como o conceito de políticas culturais em G. Canclini se transforma e abarca trocas transnacionais e o reconhecimento das regiões geoculturais e interculturais, mantendo-se vigente em reflexões contemporâneas deste campo. Além disso, introduzimos a questão do território e da dimensão espacial no estudo das políticas culturais a partir de dois outros pensadores latino-americanos, Rodolfo Kusch e Milton Santos.

As pesquisas sobre políticas culturais têm profundas variantes teóricas, me- todológicas e inclusive epistemológicas, mas poderíamos afirmar que um dos pressupostos mais sólidos destes trabalhos é a defesa de três dimensões básicas na análise desde fenômeno: a política, a econômica e a cultural ${ }^{15}$. Cada uma destas dimensões tem a sua singularidade, mas também relações e interconexões com as outras, próprio da natureza plural e transversal das políticas culturais. As combinações são tão diversas como a área de abrangência deste fenômeno, que inclui desde a indústria cultural até a economia criativa, passando pela economia política da comunicação e da cultura, as culturas populares e identitárias, as tecnologias da informação e da comunicação e as culturas digitais, entre tantas outras.

Assumindo que a política, a economia e a cultura sejam, efetivamente, as três dimensões básicas para o estudo das políticas culturais; será que são suficientes para a compreensão deste fenômeno na contemporaneidade? Quais seriam os desdobramentos que a indissociabilidade entre território/espaço geográfico e cultura poderia significar para o estudo e a gestão das políticas culturais? Alguns geógrafos têm demonstrado interesse nesta temática, gerando, inclusive, uma ramificação denominada geografia cultural. Ainda assim, uma primeira aproximação deste campo mais específico de conhecimento revela um desconhecimento sobre a tradição de pensamento latino-americano, especialmente nestes três autores aqui comentados, que discutem, há décadas, as relações entre cultura e território.

Para que não se cometam injustiças, podemos destacar o trabalho de alguns pesquisadores como ALBINATI, 2010; SERPA, 2011; BORGES e SERPA, 2012, bem como outros em andamento, que trabalham sobre a relação entre território, cultura, políticas públicas e políticas culturais. Podemos ainda citar as pesquisas de José Tasat $(2009,2010)$ e equipe (TASAT 
e MENDES CALADO, 2010), na UNTREF, sobre gestão territorial da cultura na Argentina; as pesquisas do prof. Carlos Vladimir Zambrano (2001) sobre Governabilidade Cultural e Territorial na Colômbia; Arturo Escobar $(1999,2010)$ e Eduardo Restrepo (2005) sobre os territórios da diferença e as comunidades negras do pacífico colombiano; Tício Escobar (2012) sobre terra, território e guaranis em Paraguai, entre outros.

Este texto procurou realizar um breve exercício de recapitulação de três momentos conceituais chaves na clássica definição de Néstor García Canclini e seu diálogo com a questão territorial em Rodolfo Kusch e Milton Santos. Há, contudo, a necessidade de novas reflexões inseridas nas chamadas regiões ou blocos geoculturais contemporâneos que incluam nos seus estudos dimensões sócio-espaciais como o território e o espaço geográfico, elementos indissociáveis das sociedades latino-americanas e, claro, das políticas culturais.

\section{Bibliografia}

ALBINATI, M. Assistir, Entrar em Cena ou Roubar a Cena? - Políticas Culturais no Território de Alagados (Salvador-BA). Dissertação (mestrado) - Universidade Federal da Bahia, Faculdade de Comunicação, Salvador, 2010. $136 f$.

ANDER-EGG, E. La política cultural a nivel municipal. Buenos Aires: Lumen Hvmanitas, 2005.

BARBALHO, A. Movimentos sociais, territórios interculturais e direitos: Pensando a partir do Movimento dos Trabalhadores Rurais Sem-Terra (MST). In: Anais ANPOG. $36^{\circ}$ ENCONTRO ANUAL DAANPOCS. ÁGUAS DE LINDÓIA - SP, 2012.

BARBALHO, A. Política Cultural. Coleção Política e Gestão Culturais. Salvador: P55 Edições / Secretaria de Cultura do Estado da Bahia, 2013.

BARBALHO, A. Política Cultural. In: RUBIM, L.
(Org.) Organização e produção da cultura. Salvador: EDUFBA; FACOM/CULT, 2005, p. 33-52. Disponível em: http://www.repositorio.ufba.br/ri/handle/ufba/146 Acesso em: 4 de janeiro de 2015.

BARBALHO, A. Políticas e indústrias culturais na América Latina. Revista Contemporânea. Ed.17, Vol. 9, N1, 2011. UERJ, Rio de Janeiro. Disponível em: http://www.e-publicacoes.uerj.br/ojs/index. php/contemporanea/article/view/1195 Acesso em: 4 de janeiro de 2015.

BARBOSA, F. da S.; ARAÚJO, H. E. Cultura Viva: avaliação do programa arte, educação e cidadania. Brasília: IPEA, 2010.

BARROS, J. M. Processos (trans)formativos e a gestão da diversidade cultural. In: CALABRE, L. Políticas culturais: reflexões sobre gestão, processos participativos e Desenvolvimento. São Paulo: Itaú Cultural; Rio de Janeiro: Fundação Casa de Rui Barbosa, 2009. p. 63-65.

BARROS, J. M. A mudança da cultura e a cultura da mudança: cultura, desenvolvimento e transversalidade nas políticas culturais. In: BARROS, J. M.; OLIVEIRA Jr., J. (org). Pensar e Agir com a Cultura: desafios da gestão cultural. Belo Horizonte: Observatório da Diversidade Cultural, 2011.

BARTHE-DELOIZY, F.; SERPA, A. (Org.). Visões do Brasil: Estudos culturais em geografia. Salvador: EDUFBA; Edições L'Harmattan, 2012.

BORGES, S.; SERPA, A. O papel dos agentes públicos e da sociedade civil na implementação de políticas de desenvolvimento territorial no Estado da Bahia: uma análise preliminar. Revista Geografares, $n^{\circ} 11$, p.31-59, Junho, 2012.

BOTELHO, I. Dimensões da cultura e políticas públicas. Revista São Paulo em perspectiva, São Paulo: Abr-Jun, Vol. 15, № 2, p. 73-83, 2001.

BRUNNER, J. J. Políticas culturales y democracia: hacia una teoría de las oportunidades In: GARCíA CANCLINI, N. (ed.). Políticas Culturales en América Latina. México: Grijalbo, 1990. [1987].

CALABRE, L. História das políticas culturais na América Latina: um estudo comparativo de Brasil, Argentina, México e Colômbia. Revista Escritos, Ano 7, No 7 . Rio de Janeiro: FCRB, 2013, p. 323-345.

ESCOBAR, A. Comunidades Negras de Colombia: en defensa de biodiversidad, territorio y cul- 
tura. Biodiversidad, n. 22, p. 15-20, Dic. 1999. Disponível em: http://aescobar.web.unc.edu/files/2013/09/biodiv223aescobar.pdf Acesso em: 4 de janeiro de 2015 .

ESCOBAR, A. Territorios de diferencia: Lugar, movimientos, vida, redes. Popayán: Envión Editores, 2010 [2008]. Trad. Eduardo Restrepo. Disponível em: http://aescobar.web.unc.edu/files/2013/09/Territorios.pdf Acesso em: 4 de janeiro de 2015.

ESCOBAR, T. Los tiempos múltiples. Entrevista de Julio Ramos. Revista Casa de las Américas No. 269, octubre-diciembre/2012, p. 110-125. Disponível em: http://www.casa.cult.cu/publicaciones/ revistacasa/269/entrevista.pdf Acesso em: 4 de janeiro de 2015.

FERNANDES, B. M. Entrando nos territórios do Território [2008]. In: FERNANDES, B. M. Construindo um estilo de pensamento na questão agrária: o debate paradigmático e o conhecimento geográfico. Tese (livre-docência). Presidente Prudente: UNESP, 2013, p. 190-220.

GARCÍA CANCLINI, N. Definiciones en transición. In: Mato D. (Comp). Estudios Latinoamericanos sobre cultura y transformaciones sociales en tiempos de globalización. Buenos Aires: CLACSO, 2001.

GARCÍA CANCLINI, N. Introducción. Políticas Culturales y crisis de desarrollo: un balance latinoamericano. In: GARCÍA CANCLINI, N. (ed.). Políticas Culturales en América Latina. México: Grijalbo, 1990. [1987].

GARCÍA CANCLINI, N. Políticas culturais na América Latina. Novos Estudos Cebrap, São Paulo, v. 2, n. 2, p. 39-51, jul. 1983. Trad. Wanda Caldeira Brant.

GARRETÓN, M. A. (Coord.) El Espacio Cultural Latinoamericano. Santiago: CFE/CAB, 2003.

HAESBAERT, R. Hibridismo, Mobilidade e Multiterritorialidade numa Perspectiva Geográfico-Cultural Integradora. In: SERPA, A. (org.). Espaços culturais: vivências, imaginações e representações. Salvador: EDUFBA, 2008.

HAESBAERT, R. O mito da desterritorialização: do fim dos "territórios" à multiterritorialidade. Rio de Janeiro: Bertrand Brasil, 2006. [2004].

HAESBAERT, R.; MONDARDO, M. Transterritorialidade e antropofagia: territorialidades de trânsito numa perspectiva brasileiro-latino-ame- ricana. Revista GEOgraphia, Niterói: RJ, Vol. 12, No 24, 2010.

KUSCH, R. Planteo de un arte americano. Rosario: Fund. Ross, 2012a. [1959].

KUSCH, R. América Profunda. Rosario: Fund. Ross, 2012b. [1962].

$\mathrm{KUSCH}, \mathrm{R}$. El pensamiento indígena y popular en América. Rosario: Fund. Ross, 2012c. [1970].

KUSCH, R. Geocultura del Hombre Americano. Rosario: Fund. Ross, 2012e. [1975].

$\mathrm{KUSCH}, \mathrm{R}$. Esbozo de una antropología filosófica americana. Rosario: Fund. Ross, 2012f. [1978].

KUSCH, R. Obras completas. Tomo I, II, III e IV. Rosario: Fund. Ross, 2007.

LANGÓN, M. Geocultura. In: SALAS ASTRAIN, R. (dir.). Pensamiento Crítico Latinoamericano: Conceptos Fundamentales. Santiago de Chile: U. Católica Silva Henríquez, 2005, v. II.

MATO, D. Cultura, comunicación y transformaciones sociales en tiempos de globalización. In: Cultura y Transformaciones sociales en tiempos de globalización: Perspectivas latinoamericanas. MATO, D.; MALDONADO FERMÍN, A. (comp.). Buenos Aires: CLACSO, 2007a.

MATO, D. Importancia de los referentes territoriales en procesos transnacionales. Estudos de Sociologia, Araraquara: São Paulo, v.12, n.23, 2007b. p. 35-63. Disponível em: http://seer.fclar.unesp.br/ estudos/article/view/499 Acesso em: 4 de janeiro de 2015.

MATO, D. Todas las industrias son culturales. Nueva época, núm. 8, julio-diciembre, 2007c. p. 131-153. Disponível em: http://www.publicaciones. cucsh.udg.mx/pperiod/comsoc/pdf/cys8_2007/ cys_n8_7.pdf Acesso em: 4 de janeiro de 2015.

MATO, D. Contextos, conceptualizaciones y usos de la idea de interculturalidad. In: AGUILAR, M. et al (Eds.) Pensar lo contemporáneo: De la cultura situada a la convergencia tecnológica. (p. 28-50). Barcelona and México: Anthropos y Universidad Autónoma Metropolitana-Iztapalapa, 2009.

MATO, D. Heterogeneidad social e institucional, interculturalidad y comunicación intercultural. MATRIZes. Vol 6, No 1-2. São Paulo, Jul/Dez, 2012. p. 43-61. Disponível em: http://www.matrizes.usp. 
br/index.php/matrizes/article/view/376 Acesso em: 4 de janeiro de 2015.

MORAES, A. C. R. Bases da formação territorial do Brasil. GEOGRAFARES, Vitória, no 2, jun. 2001. p. 105-113.

NIVÓN BOLÁN, E. Desarrollo y debates actuales de las políticas culturales en México, (texto sin publicar), 2008. Disponível em: http://sgpwe.izt. uam.mx/files/users/uami/nivon/NIVON_EDUARDO_Pol_Cultural_Mexico.pdf Acesso em: 4 de janeiro de 2015.

PORTO-GONÇALVES, C. W. A globalização da natureza e a natureza da globalização. Rio de Janeiro: Civilização Brasileira, 2012. [2006].

PORTO-GONÇALVES, C. W. De saberes e de territórios: diversidade e emanicapação a partir da experiência latino-americana. In: CECEÑA, Ana Esther (coord.). De los saberes de la emancipación y de la dominación. Buenos Aires: Consejo Latinoamericano de Ciencias Sociales - CLACSO, 2008.

RESTREPO, E. Políticas de la teoría y dilemas de los estudios de las colombias negras. Popayán: Editorial Universidad del Cauca. 2005. Disponível em: http://www.ram-wan.net/restrepo/publicaciones.htm Acesso em: 4 de janeiro de 2015.

RESTREPO, E. Antropología y estudios culturales: Disputas y confluencias desde la periferia. Buenos Aires: Siglo Veintiuno Editores, 2012.

RUBIM, A. A. C. Políticas culturais: entre o possível e o impossível. In: NUSSBAUMER, G. M. Teorias e politicas da cultura: visões multidisciplinares. Salvador: EDUFBA, 2007.

SAQUET, M. A. Abordagens e concepções de território. 2. ed. São Paulo: Expressão Popular, 2010 [2007].

SANTOS, M. Metamorfoses do Espaço Habitado: fundamentos teóricos e metodológicos da geografia. São Paulo: Edusp, 2012a [1988].

SANTOS, M. A natureza do espaço: técnica e tempo, razão e emoção. São Paulo: Edusp, 2012b [1996].

SANTOS, M. Por uma outra globalização: do pensamento único à consciência universal. Rio de Janeiro: RECORD, 2010 [2000].

SANTOS, M. O retorno do território. In: OSAL: Ob- servatorio Social de América Latina. Año 6 no. 16 (jun.2005). Buenos Aires: CLACSO, 2005 [1994], p. 251-261.

SANTOS, M. Território e Sociedade: Entrevista com Milton Santos. São Paulo: Fundação Perseu Abramo, 2001 [2000].

SANTOS, M.; SILVEIRA, M. L. O Brasil: território e sociedade no inicio do século XXI.Rio de Janeiro: RECORD, 2011 [2001].

SERPA, A. (Org.). Cidade popular: trama de relações sócio-espaciais. Salvador: EDUFBA, 2007.

SERPA, A. Políticas públicas e o papel da geografia. In: Revista da ANPEGE, v. 7 , n. 1, número especial, p. 37-47, out. 2011.

SODRÉ, M. O terreiro e a cidade: A forma social negro-brasileira. Rio de Janeiro: Imago Ed.; Salvador: FUNCEB, 2002. [1988].

TASAT, J. Políticas Culturales de los gobiernos locales en el conurbano bonaerense. In: Indicadores Culturales 2008. Caseros: EDUNTREF, 2009. p. 185-191.

TASAT, J. Políticas Culturales de los gobiernos locales en el conurbano bonaerense (segunda parte). In: Indicadores Culturales 2009. Caseros: EDUNTREF, 2010. p. 61-70.

TASAT, J.; MENDES CALADO, P. Indicadores presupuestarios: Dispositivos para la gestión de gobiernos locales. In: Indicadores Culturales 2009. Caseros: EDUNTREF, 2010. p. 33-39.

TEIXEIRA COELHO. Dicionário Crítico de Política Cultural: Cultura e Imaginário. São Paulo: Iluminuras, 1997.

TEIXEIRA COELHO. Dicionário Crítico de Política Cultural: Cultura e Imaginário. $2^{\mathrm{a}}$ ed., [rev. e ampl.]. São Paulo: lluminuras, 2012.

ZAMBRANO, C. V. Territorios plurales, cambio sociopolítico y gobernabilidad cultural. In: Boletim Goiano de Geografia 21(1): 09-49, jan/jul, 2001.

\section{Recebido em 09/01/2015 Aprovado em 15/02/2015}


1 Juan Ignacio Brizuela, pesquisador visitante na Universidade Federal da Bahia, Brasil. Contato: juanbrizuelapna@gmail.com

2 José Márcio Pinto de Moura Barros, doutor em Comunicação e Cultura, Professor Titular da Universidade do Estado de Minas Gerais, Brasil. Contato: josemarciobarros@gmail.com

3 Experiências similares de organização estatal do campo da cultura podem ser observadas, também, na mesma época, na Colômbia e no México.

4 Esta crítica do jovem García Canclini ao ensaio e à filosofia latino-americana não durará muito já que ele mesmo contribuirá com a vigência do ensaio latino-americano no premiado texto "Latinoamericanos buscando un lugar en este siglo" (2002).

5 O Conselho Latino-americano de Ciências Sociais (CLACSO) é uma instituição internacional não governamental, fundada em 1967, que mantém relações formais com a UNESCO. Através de diversas parecerias e atividades de ensino e pesquisa, busca contribuir a repensar, a partir de uma perspectiva crítica e pluralista, a problemática integral das sociedades da América Latina e Caribe. Informação disponível em: http://www.clacso. org.ar/institucional/1a.php?idioma=port Acesso em: 4 de janeiro de 2015

6 O livro organizado por Daniel Mato onde García Canclini participa foi publicado em junho de 2001 ; isto é, três meses antes do atentado.

7 "Uno de los pocos consensos que existe hoy en los estudios sobre cultura es que no hay consenso. No tenemos un paradigma internacional e interdisciplinariamente aceptado, con un concepto eje y una mínima constelación de conceptos asociados, cuyas articulaciones puedan contrastarse con referentes empíricos en muchas sociedades. Hay diversas maneras de concebir los vínculos entre cultura y sociedad, realidad y representación, acciones y símbolos" (GARCÍA CANCLINI, 2001, p. 57).

8 "Necesitamos, sin embargo, algunas definiciones operativas, aunque sean provisionales e inseguras, para seguir investigando y hacer políticas culturales. Todos arbitramos de algún modo en conflictos entre tendencias epistemológicas cuando elegimos nuestro objeto de estudio, ponemos en relación un conjunto de comportamientos con un repertorio de símbolos, y seguimos una ruta para buscar los datos, ordenarlos y justificarlos" (Ibídem, p. 57).

9 Sobre território, por exemplo, podemos consultar obras de autores como Antonio Carlos Robert de Moraes (2001), Arturo Escobar (1999, 2010), Bernardo Mançano Fernandes (2013), Carlos Walter Porto-Gonçalves (2008, 2012), Daniel Mato (2007a), Marcos Aurélio Saquet (2010), Milton Santos (2001, 2010, 2012a, 2012b), Muniz Sodré (2002), Rodolfo Kusch (2012b, 2012e, 2012f) e Ro- gério Haesbaert (2006, 2008). Sobre políticas culturais, encontramos reflexões de Albino Rubim (2007), Alexandre Barbalho (2005, 2011, 2013), Eduardo Nivón Bolán (2008), Ezequiel Ander-Egg (2005), Frederico Barbosa da Silva (2010), Isaura Botelho (2001), José Joaquin Brunner (1990), José Márcio Barros (2009, 2011), Lia Calabre (2013), Néstor García Canclini (1983, 1990, 2001), Teixeira Coelho $(1997,2012)$, entre outros. Além disso, eventos científicos como o ENECULT realizado pelo CULT/UFBA, diversos encontros organizados pela Fundação Casa Rui Barbosa - FCRB com destaque para o Seminário Internacional de Políticas Culturais, os Encontros Estaduais e Brasileiros sobre Políticas Culturais e os Congressos de Cultura Viva Comunitária - Pontos de Cultura corroboram essa crescente preocupação e produção nesta área.

10 Em palavras do autor: "O que ele [o território] tem de permanente é ser nosso quadro de vida. Seu entendimento é, pois, fundamental para afastar o risco da alienação, o risco de perda de sentido da existência individual e coletiva, o risco de renúncia ao futuro" (SANTOS, 2005 , p. 255, colchetes nossos).

11 Costuma distinguir-se o "espaço" como categoria geral de análise, mais vago, do "território" como conceito mais "preciso" do ponto de vista epistemológico (MORAES apud HAESBAERT, 2006, p. 37). Roberto Lobato Corrêa, na orelha do livro de Haesbaert, também considera o território como uma conceituação derivada do espaço, o conceito maior. Contudo, Milton Santos, nos seus últimos escritos, deixa de considerar relevante esta distinção, questão que discutimos no primeiro capítulo da tese.

12 Segundo Haesbaert: "[...] o argumento da desterritorialização e o projeto neoliberal caminham juntos, um a serviço do outro" (2006, p. 24).

13 As trocas intelectuais que acontecem, por exemplo, em países como Itália, França, Alemanha e Grã Bretanha, foram estudadas minuciosamente por pesquisadores brasileiros como Haesbaert $(2006,2008)$ ou Saquet (2010).

14 "Afirmar que la geografía condiciona el pensamiento sería muy superficial. Pero enunciemos siquiera a nivel hipotético que algo más profundo ocurre, y que no lo conocemos y que caracterizamos el problema con el término suelo" (Ibidem, p. 78, itálicas do autor).

15 Desde 2003, com a chegada ao poder do presidente Luis Inácio "Lula" Da Silva, muitas pastas de cultura nacionais, estaduais e municipais adotaram a tridimensionalidade da cultura (no seu sentido mais amplo, também chamado de antropológico) nas suas dimensões cidadã (política), econômica e simbólica (cultural, em sentido estrito).

16 Cincinato Marques de Souza Júnior, Cartografia nas Metas do Plano Nacional de Cultura e Luciano Simões de Souza, Me conta Universidade livre do Médio Rio das Contas: cultura, participação e desenvolvimento local. Teses em andamento do Doutorado em Cultura e Sociedade - Universidade Federal da Bahia. Início: 2012. 